\title{
Recurrent gastrointestinal stromal tumor (GIST) of the stomach associated with a novel $c$-kit mutation after imatinib treatment
}

\author{
Tomoki Koyama, Hiroshi Nimura, Katsutoshi Kobayashi, Hideki Marushima, Hironori Odaira, \\ Hirotaka Kashimura, Norio Mitsumori, and Katsuhiko Yanaga \\ Department of Surgery, The Jikei University School of Medicine, 3-25-8 Nishishinbashi, Minato-ku, Tokyo 105-8461, Japan
}

\begin{abstract}
A 57-year-old man with gastrointestinal stromal tumor (GIST) of the stomach with peritoneal dissemination underwent gastrectomy. After surgery, he was treated with $400 \mathrm{mg}$ / day of imatinib, without recurrence, for 26 months. At 26 months, the imatinib dose was reduced because of nausea, and 4 months after the dose reduction, recurrence of GIST was detected, for which surgical resection was performed again. The first surgical specimen had a mutation of exon 11 in the ckit receptor gene. Intriguingly, the second surgical specimen had a novel mutation of exon 17 , in addition to the abovementioned mutation, in the $c$-kit receptor gene. Based on the result of molecular analysis, the novel mutation of exon 17, induced by longterm chemotherapy, was judged to have been responsible for the recurrence, which perhaps was triggered by the dose reduction of imatinib.
\end{abstract}

Key words Gastrointestinal stromal tumor - Imatinib · Resistance $\cdot c$-kit $\cdot$ Mutation

\section{Introduction}

Gastrointestinal stromal tumors (GISTs) account for the majority of gastrointestinal mesenchymal tumors, including leiomyosarcomas and leiomyoblastomas. Most GISTs express c-kit receptor tyrosine kinase (KIT) [1]. Although surgery used to be the only valid therapy for GISTs, imatinib mesylate, a multitargeted tyrosine kinase inhibitor, has recently been reported to be effective therapy for GIST [2]. Nevertheless, several reports to date indicate that the acquisition of $c$-kit gene mutations can result in resistance to imatinib treatment $[3,4]$. We report a patient who developed recurrent GIST, in association with the development of a secondary mutation in the $c$-kit receptor gene.

Offprint requests to: T. Koyama

Received: November 8, 2005 / Accepted: February 14, 2006

\section{Case report}

A 57-year-old man was referred to our hospital because of a submucosal tumor in the stomach. Upper gastrointestinal endoscopy revealed an elevated lesion, with a deep central depression, in the greater curvature of the gastric body. Biopsy specimens indicated GIST. He underwent laparotomy, in which an extramural tumor $14 \mathrm{~cm}$ in diameter, was found in the lower gastric body; there was also a great account of peritoneal dissemination. He underwent distal gastrectomy without lymphadenectomy. Two tumors, each approximately $5 \mathrm{~cm}$, in the peritoneum were also resected. GIST in the stomach was confirmed by pathological and immunohistochemical examinations, which demonstrated an interlacing pattern of spindle cells, and positive staining for CD117 (Fig. 1) and CD34, with staining for smooth muscle actin and S-100 protein being negative.

Postoperatively, daily administration of imatinib $(400 \mathrm{mg} /$ day) was started, and no recurrence was observed on imaging studies done during the next 26 mos; there were no side effects during this time. However, at 26 months, the dose had to be reduced to $200 \mathrm{mg}$ per day, because of gastrointestinal toxicity (nausea). Four months after the first dose reduction, intraabdominal recurrence was suspected, shown by computed tomography (CT; Fig. 2B).

The dose of imatinib was therefore gradually increased, back to $400 \mathrm{mg}$ per day. However, the recurrent tumor continued to grow, and he underwent reoperation. Peritoneal dissemination was not observed, and resection of the remnant tumor was carried out with combined colonectomy. After this operation, imatinib treatment was again started, and there has been no recurrence for the 7 months since the second operation.

Mutations of the KIT receptor and platelet-derived growth factor receptor alpha $(P D G F R A)$ genes were 

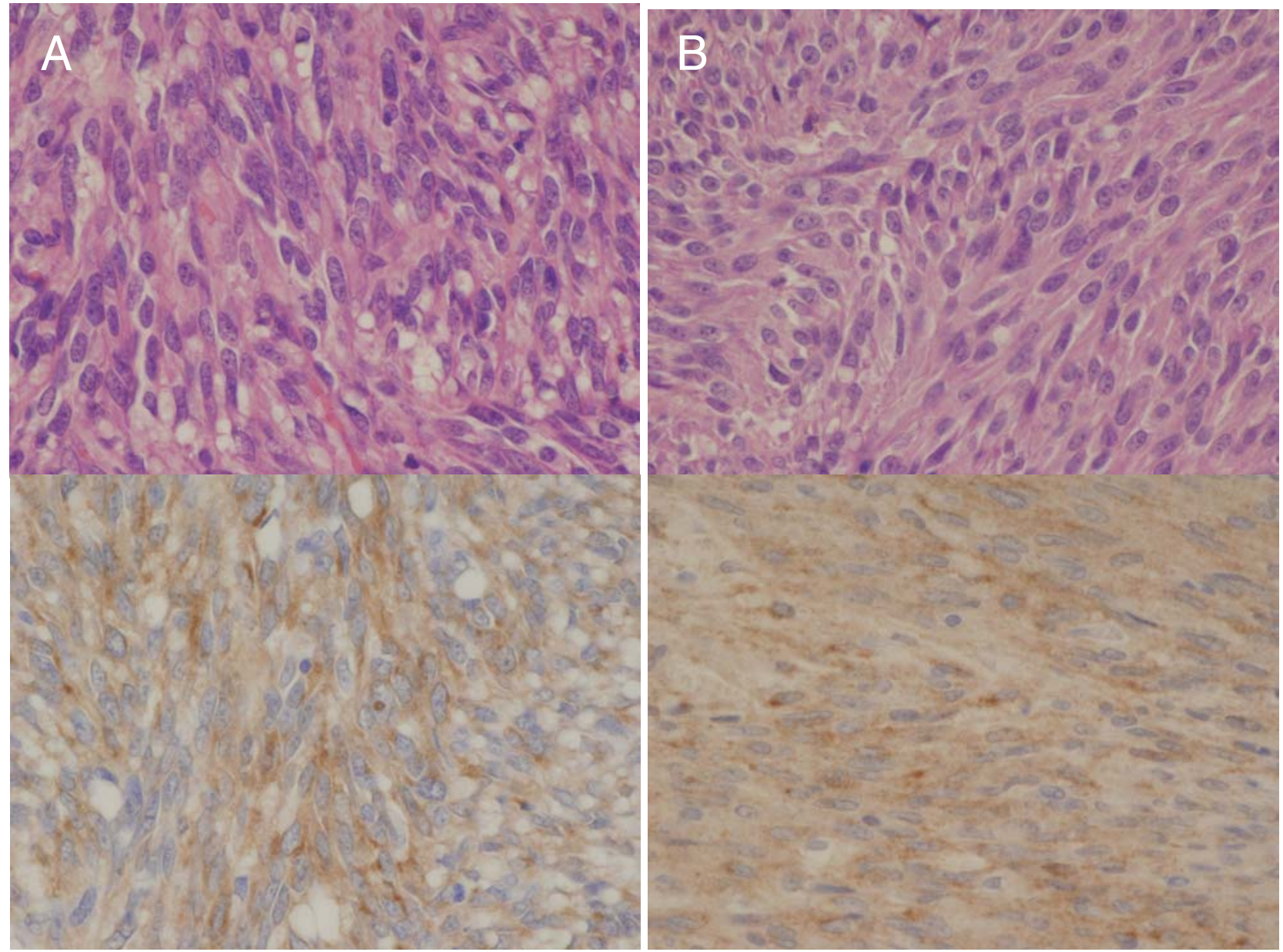

Fig. 1A,B. Histological appearance of the surgical specimens of $\mathbf{A}$ the first and $\mathbf{B}$ the second operation. The pathological finding showed an interlacing pattern of spindle cells. Both specimens were positive for KIT. Upper panels, H\&E $\times 200 ;$ lower panels, CD117 (KIT) immunostaining $\times 200$

studied in the surgical specimens. We investigated exons $9,11,13$, and 17 for the KIT receptor gene and exons 12 and 18 for the PDGFRA, gene, because these exons have been reported as hot spots for mutations. The first surgical specimen had a deletion mutation (codon 564-578 : AAT GGA AAC AAT TAT GTT TAC ATA GAC CCA ACA CAA CTT CCT TAT / $45 \mathrm{bp}$ del) in exon 11 of the $c$-kit receptor. In the specimen from the second operation, a novel point mutation (Asp820His) in the c-kit receptor gene, in addition to the deletion mutation, in exon 11, was identified in exon 17 (Fig. 3).

\section{Discussion}

GISTs commonly carry an activating mutation of the $K I T$ gene [1], or less often, a mutation in the PDGFRA gene [5]. KIT is a gene product of the v-kit HardyZuckerman 4 feline sarcoma viral oncogene homolog
(KIT), and shows type III receptor tyrosine kinase activity. Most GISTs have oncogenic KIT mutations within exon 9 or exon 11 in the kit receptor gene, which encode parts of the extracellular and intracellular juxtamenbrane regions, respectively. In addition, there are a few GISTs that have mutations within exon 13 or exon 17 in the kinase domain of the kit receptor. All $c$ kit mutations in GISTs, irrespective of the affected domain, appear to be associated with gain of function, as manifested by constitutive KIT tyrosine phosphorylation [1].

Imatinib mesylate (STI 571), a phenylaminopyrimidine derivative, is a small molecule that selectively inhibits the enzymatic activity of several tyrosine kinases, including $\mathrm{ABL}$; the $\mathrm{BCR}-\mathrm{ABL}$ fusion protein of chronic myeloid leukemia and Philadelphia chromosome-positive acute lymphoblastic leukemia; PDGFR; and the product of the KIT gene [6,7]. Recently, several clinical trials have demonstrated that imatinib was effective for metastatic and recurrent 

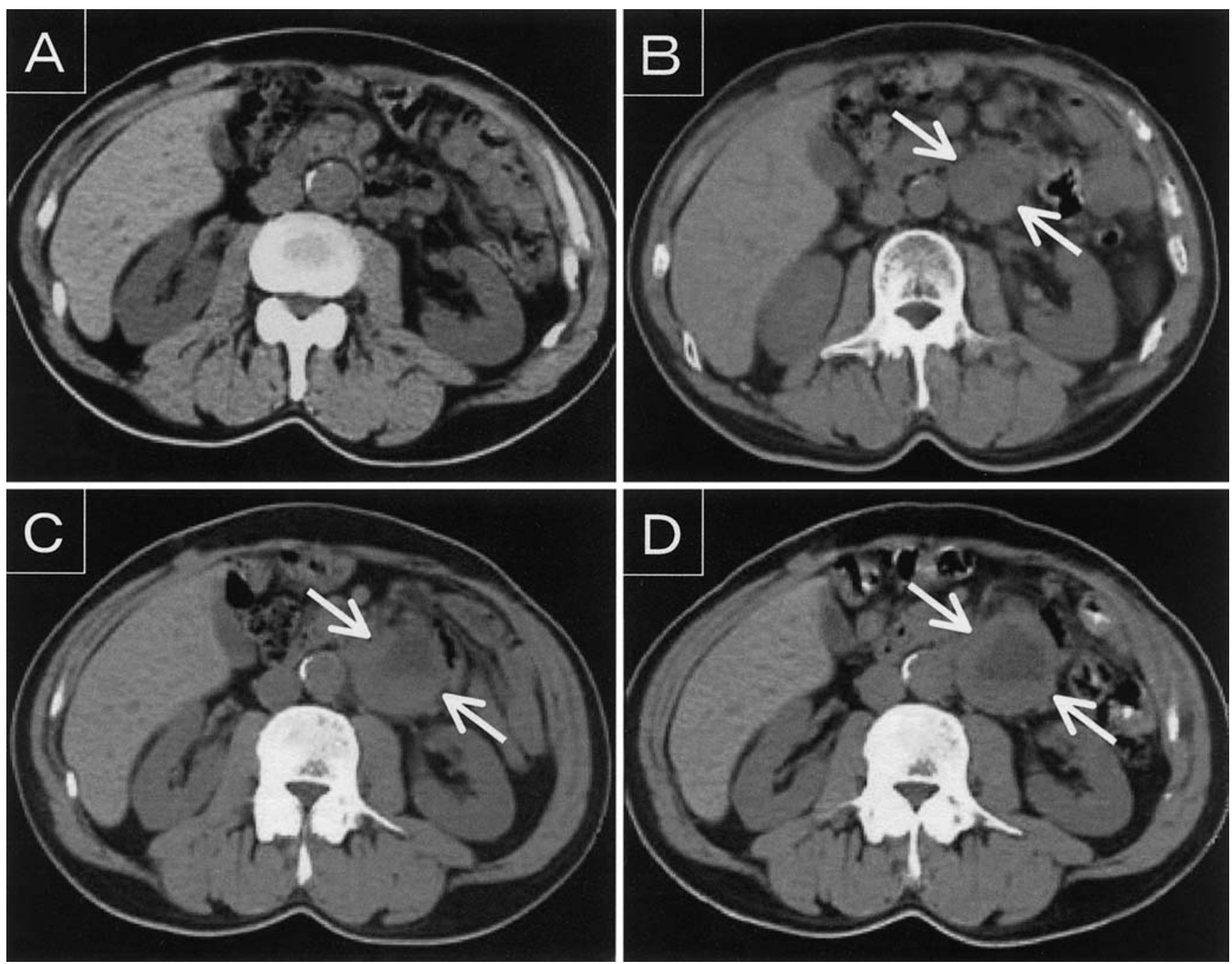

Fig. 2A-D. Serial computed tomography (CT) scans. A At 24 months after the first operation, no recurrence was detected. B At 30 months, 3 months after the initiation of imatinib dose reduction, a 4-cm tumor was detected (arrows). C Two months after the time the scan shown in $\mathbf{B}$ was taken, the tumor size had increased (arrows). D At 35 months after the first operation, the tumor was $6 \mathrm{~cm}$ in diameter (arrows). The patient then underwent reoperation

GISTs [8-10]. On the other hand, some GISTs are resistant to imatinib from the beginning (primary resistance), or they acquire resistance after the initial response or disease stabilization (acquired resistance).

The efficiency of and resistance to imatinib treatment for GIST depend on where the mutation is located. In GISTs with the exon 11 mutation in $c$-kit, imatinib treatment is effective. However, the therapeutic effect of imatinib may not be as good if exon 17 is mutated. Exon 17 is located in the tyrosine kinase II domain, and this domain is a portion of the adenosine triphosphate (ATP) binding site. Imatinib competes with ATP for the ATP-binding site of the kinase, preventing downstream signaling. Thus, a point mutation of exon 17 inhibits imatinib binding to the ATP-binding site, resulting in constitutive and strong activation of KIT phosphorylation $[2,11]$.

At present, the mechanism underlying the development of a second mutation in GIST is unclear. It is known that, in patients on prolonged imatinib therapy, resistance is acquired by a median time of 27 months. Several mechanisms for biological imatinib resistance have been suggested [3,12]: (A) acquisition of a new c-kit or PDGFRA point mutation, coexpressed with pre-imatinib mutations in the same genes, with the resultant strong phosphorylation of KIT or PDGFRA; (B) KIT genomic amplification with overexpression of the KIT oncoprotein, without a new point mutation; and $(C)$ activation of other types of tyrosine kinase receptor. 


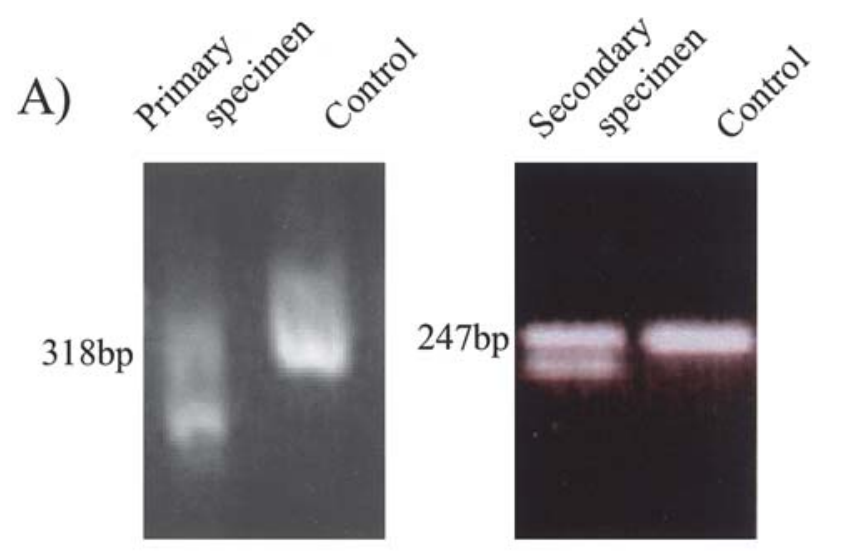

B)

codon 564-578

AAT GGA AAC AAT TAT GTT TAC ATA GAC CCA ACA CAA CTT CCT

TAT /45bp del

\section{C) Exon 17 Point mutation}

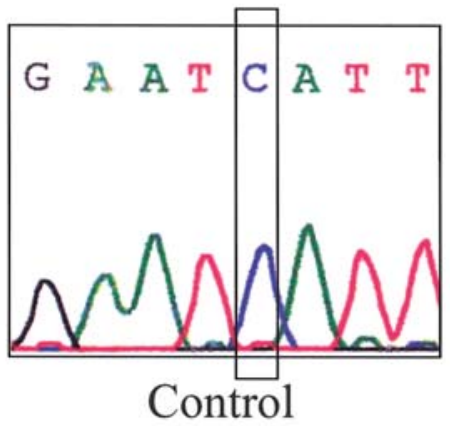

Control
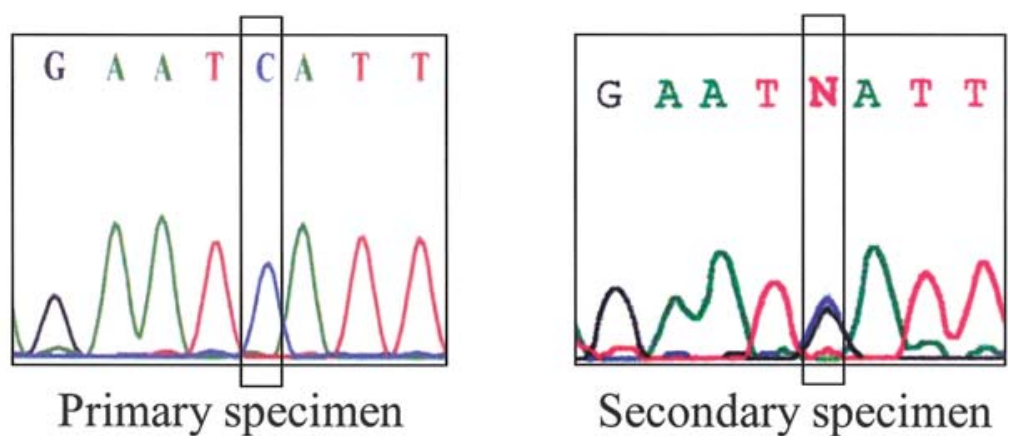

Secondary specimen

\section{Point mutation (Asp 820 His)}

Fig. 3A-C. Analysis of $c$-kit gene DNA from the second surgical specimen. A Left panel of agarose electrophoresis shows lower band shift of DNA fragment in primary tumor specimen. The same change was observed in DNA from the secondary tumor. DNAs in the left panel were extracted from formalin-fixed paraffin embedded tissues, and those in the right panel were extracted from frozen specimens. In the primary and secondary specimens, an exon 11 mutation

In our patient, a novel mutation in exon 17 of the kit receptor was demonstrated in a recurrent lesion after 2 years of treatment, which suggests that the recurrence was caused by mechanism (A) above. Thus, the novel mutation was thought to be related to imatinib resistance, although we are not sure whether the novel mutation was either acquired or selected during the 2 years' imatinib treatment. It has also been documented that the cessation of imatinib or subtherapeutic levels the drug during stable measurable disease results in tumor proliferation [13]. The recurrence and resistance that followed imatinib treatment in our patient may have been related to the dose reduction of imatinib. (deletion) in the KIT receptor was identified by sequence analysis of the upper and lower bands. We used human placenta-origin genomic DNA as control. B The lower band in the tumor specimens turned out to be a deletion mutation of exon 11 in the $c$-kit receptor gene, shown by the sequence analysis. C In the secondary tumor, a novel point mutation (GAT820CAT, Asp820His) in the c-kit receptor was identified

\section{References}

1. Hirota S, Isozaki K, Moriyama $\mathrm{Y}$, Hashimoto $\mathrm{K}$, Nishida $\mathrm{T}$, Ishiguro S, et al. Gain-of-function mutations of c-kit in human gastrointestinal stromal tumors. Science 1998;279:577-80.

2. Ma Y, Zeng S, Metcalfe DD, Akin C, Dimitrijevic S, Butterfield $\mathrm{JH}$, et al. The c-KIT mutation causing human mastocytosis is resistant to STI571 and other KIT kinase inhibitors: kinases with enzymatic site mutations show different inhibitor sensitivity profiles than wild-type kinases and those with regulatory-type mutations. Blood 2002;99:1741-4.

3. Debiec-Rychter M, Cools J, Dumez H, Sciot R, Stul M, Mentens $\mathrm{N}$, et al. Mechanisms of resistance to imatinib mesylate in gastrointestinal stromal tumors and activity of the PKC412 inhibitor against imatinib-resistant mutants. Gastroenterology 2005;128: 270-9. 
4. Tamborini E, Bonadiman L, Greco A, Albertini V, Negri T, Gronchi A, et al. A new mutation in the KIT ATP pocket causes acquired resistance to imatinib in a gastrointestinal stromal tumor patient. Gastroenterology 2004;127:294-9.

5. Hirota S, Ohashi A, Nishida T, Isozaki K, Kinoshita K, Shinomura Y, et al. Gain-of-function mutations of plateletderived growth factor receptor alpha gene in gastrointestinal stromal tumors. Gastroenterology 2003;125:660-7.

6. Heinrich MC, Griffith DJ, Druker BJ, Wait CL, Ott KA, Zigler AJ. Inhibition of c-kit receptor tyrosine kinase activity by STI 571, a selective tyrosine kinase inhibitor. Blood 2000;96:925-32.

7. Druker BJ, Tamura S, Buchdunger E, Ohno S, Segal GM, Fanning S, et al. Effects of a selective inhibitor of the Abl tyrosine kinase on the growth of Bcr-Abl positive cells. Nat Med 1996; 2:561-6.

8. Joensuu H, Roberts PJ, Sarlomo-Rikala M, Andersson LC, Tervahartiala P, Tuveson D, et al. Effect of the tyrosine kinase inhibitor STI571 in a patient with a metastatic gastrointestinal stromal tumor. N Engl J Med 2001;344:1052-6.

9. van Oosterom AT, Judson I, Verweij J, Stroobants S, Donato di Paola E, Dimitrijevic S, et al. Safety and efficacy of imatinib
(STI571) in metastatic gastrointestinal stromal tumours: a phase I study. Lancet 2001;358:1421-3.

10. Verweij J, Casali PG, Zalcberg J, LeCesne A, Reichardt P, Blay JY, et al. Progression-free survival in gastrointestinal stromal tumours with high-dose imatinib: randomised trial. Lancet 2004;364:1127-34.

11. Frost MJ, Ferrao PT, Hughes TP, Ashman LK. Juxtamembrane mutant V560GKit is more sensitive to imatinib (STI571) compared with wild-type c-kit whereas the kinase domain mutant D816VKit is resistant. Mol Cancer Ther 2002;1:1115-24.

12. Antonescu CR, Besmer P, Guo T, Arkun K, Hom G, Koryotowski B, et al. Acquired resistance to imatinib in gastrointestinal stromal tumor occurs through secondary gene mutation. Clin Cancer Res 2005;11:4182-90.

13. Blay JY, Bonvalot S, Casali P, Choi H, Debiec-Richter M, Dei Tos AP, et al. Consensus meeting for the management of gastrointestinal stromal tumors. Report of the GIST Consensus Conference of 20-21 March 2004, under the auspices of ESMO. Ann Oncol 2005;16:566-78. 